\title{
A EDUCAÇÃO AMBIENTAL E O LIXO: UM ESTUDO DE CASO REALIZADO EM UMA ESCOLA PÚBLICA DE TERESINA (PI)
}

\author{
Kelly Beatriz Maia Costa, ${ }^{1}$ \\ Micaías Andrade Rodrigues ${ }^{2}$
}

Resumo: Este artigo investigou como a Educação Ambiental (EA) e a questão do lixo como problemática ambiental podem contribuir para formação voltada à cidadania. Trata-se de um estudo de caso realizado em uma escola pública em Teresina, Piauí, que teve a participação dos educadores das diferentes áreas do conhecimento e buscou analisar se os educadores abordam a EA e a questão do lixo entre seus conteúdos. Ressaltamos que não é apenas o professor na área de ciências o responsável pelo conhecimento frente às questões ambientais, pois cada área do conhecimento pode e deve contribuir para que 0 aluno possa compreendê-la e posicionar diante dela. Para coletarmos os dados utilizamos a entrevista semiestruturada e como resultados percebemos que os professores contribuem com o favorecimento do tema em seus conteúdos de ensino e que a questão do lixo é presente como assunto interdisciplinar.

Palavras-chave: Educação Ambiental; Lixo; Meio Ambiente; Ação docente.

${ }^{1}$ Universidade Federal do Piauí. E-mail:keby.lya@hotmail.com

${ }^{2}$ Universidade Federal do Piauí. E-mail: micaias@ufpi.edu.br Revbea, São Paulo, V. 9, № 2: 344-363, 2014. 


\section{Introdução}

O tema escolhido como objeto de estudo nesta pesquisa é a Educação Ambiental (EA) usando o lixo como problemática ambiental. Silva (2010) esclarece que a EA torna-se elemento de essencial no processo de reflexão para o desenvolvimento da ação e de um comportamento consciente da sociedade. É preciso conscientizar, sensibilizar e reeducar as pessoas para que ajam de forma responsável, conservando e protegendo o meio ambiente.

Atividades relacionadas à prática da EA no sentido de procurar soluções ou mesmo aliviar os problemas ambientais devem ser desenvolvidas. Rodrigues (2010) afirma que a EA deve ser entendida como um processo dinâmico de aprendizagem, valorizando as diversas formas de conhecimento, enfocando a formação do cidadão consciente de que sua atuação transcende a determinada localidade, tornando-se ecologicamente correto.

Desta forma, cabe dizer que cada indivíduo é responsável pela transformação que causa ao meio ambiente (MA), portanto a responsabilidade de preservação e conservação é atribuída à sociedade como um todo. Rodrigues (2010) comenta que a EA pode contribuir para a formação do cidadão através de práticas pedagógicas desenvolvidas tendo como base uma nova visão do ensino formal, abordando conceitos de cidadania e sustentabilidade.

Portanto é fundamental que cada indivíduo saiba o significado de sustentabilidade e MA, pois a partir dessa visão é possível trabalhar em busca de uma melhor qualidade de vida de cada indivíduo e sociedade. Silva (2010, p.17) afirma que a EA deve ser entendida como

Uma ação política, pois reivindica uma conscientização ambiental, sobre a leitura ética das relações, e, prepara a sociedade, através de um processo de participação coletiva no qual o sujeito percebe o meio ambiente, a partir de uma reflexão direcionada á uma ação emancipatória.

Este trabalho trata-se de um estudo de caso realizado em uma escola pública municipal de Teresina - Piauí. O presente estudo discute a EA e o lixo como eixos norteadores e tem como propósito analisar como os educadores nas diferentes áreas do conhecimento abordam a EA e a questão do lixo como problema ambiental em sala de aula. Ressaltamos a importância de dizer que não apenas o educador na área de ciências é o responsável pela transmissão do conhecimento frente às questões ambientais, pois todas as áreas do conhecimento podem e devem contribuir para que o aluno possa compreendêla e posicionar diante dela. Neste entendimento, Silva (2010) esclarece que a EA em sua esfera democrática e participativa, objetiva o desenvolvimento do pensamento sustentável como meio de conscientização ambiental, onde o conhecimento é produto de uma construção participativa. 
Visando este desenvolvimento, os Parâmetros Curriculares Nacionais PCN (BRASIL, 1997) compõem os temas transversais presentes em todas as disciplinas de ensino, entre eles o tema MA. A EA, que trabalha este tema, é uma tentativa de transformação social, uma vez que a escola ainda exerce forte influência para a uma formação voltada à cidadania.

Dentro de uma variedade de questões ambientais a problemática do lixo pode ser discutida no âmbito escolar de maneira interdisciplinar, uma vez que envolve questões direcionadas não só ao MA em seu meio natural, mas à sociedade, à cultura, à economia, à saúde, etc. Assim é possível mostrar a importância da preservação e conservação do MA. O destino deste ainda gera uma problemática ambiental a ser sanada em nossos dias por consequência de um mau direcionamento deste e um aumento na sua produção.

\section{Educação Ambiental}

A Educação Ambiental tenta integrar as pessoas a partir de um conceito coletivo a fim de promover ações educativas voltadas a atividades de proteção, recuperação e melhoria na qualidade de vida social e ambiental. Tem como propósito preparar um cidadão consciente, com ações responsáveis e que se preocupa em conviver em equilíbrio com o meio. A EA provoca uma discussão a respeito das questões ambientais, como por exemplo, o impacto que um mau direcionamento do lixo provoca ao ambiente, MA e sustentabilidade.

Silva (2010, p.18) coloca a EA como:

Os processos por meio dos quais os indivíduo e a coletividade constroem valores sociais, conhecimentos, habilidades, atitudes, e competências voltadas para a conservação do meio ambiente, bem de uso comum do povo, essencial, à sadia qualidade de vida e a sustentabilidade.

Desta forma, a EA contribui para a formação do ser humano no processo construtivo de reflexão para que desenvolva ações conscientes, de maneira que os tornem cidadãos comprometidos com as mudanças referentes ao MA através de um pensamento crítico individual e coletivo que o direcione para uma vida mais sustentável. Com a EA as pessoas apreendem como funciona 0 ambiente, como dependemos dele, como o afetamos e como promovemos a sua sustentabilidade. $O$ assunto surge nos dias atuais como uma proposta desafiadora em busca da reeducação das pessoas em relação ao MA e tudo o que o cerca.

Silva (2010) comenta que o termo Educação Ambiental foi criado durante a Conferência de Educação da Universidade de Keele, Inglaterra em 1965, como recomendação de que deveria tornar-se parte essencial da educação de todos os cidadãos. Afirma ainda (idem) que em 1968, a Unesco realizou um estudo sobre MA e escola, o qual confirmou que a EA não deve ser Revbea, São Paulo, V. 9, № 2: 344-363, 2014. 
instituída como uma disciplina obrigatória curricular, uma vez que esta é interdisciplinar. Sendo assim, o MA não deverá ser considerado apenas em seu meio natural, mas abrangendo um conjunto de fatores que o cerca e com o qual ele interage.

A primeira Conferência Intergovernamental em Educação Ambiental, ocorrida em Tbilisi, em 1977, discutiu a sua natureza, objetivos, características e estratégias em EA relacionadas nos planos nacionais e internacionais baseando-se no Programa Internacional de Educação Ambiental (SILVA, 2010). Nela também definiu-se a EA como a dimensão dada ao conteúdo e à prática da educação orientada para a resolução dos problemas concretos do MA por meio da interdisciplinaridade e da participação ativa e responsável de todos.

Partindo desse princípio a EA é um processo de ensino e aprendizagem que permite analisar e compreender o MA em seus aspectos sociais, econômicos, culturais que são estabelecidos entre o sujeito e o meio, a fim de se construir um pensamento crítico voltado à preservação ambiental, conservação, sustentabilidade e responsabilidade social.

A Constituição Brasileira de 1988 (BRASIL, 1988) capítulo VI e, art. 225 enfatiza que "todos tem o direito ao Meio Ambiente ecologicamente equilibrado, bem de uso comum do povo e essencial a sadia qualidade de vida, impondo-se ao poder público e a coletividade o dever de defendê-lo e preservá-lo para as presentes gerações futuras" e que a EA deve ser promovida em todos os níveis de ensino e conscientização pública para a preservação do MA.

A Lei $n^{\circ}$ 9.795/99 (BRASIL, 1999) dispõe sobre EA e instituiu a Política Nacional de Educação Ambiental (PNEA) e oferece amparo legal à EA, responsabilizando e envolvendo todos os setores da sociedade e propondo a sua integração em todas as disciplinas, porém não como disciplina específica no currículo de ensino e define EA como

os processos por meio dos quais o indivíduo e a coletividade constroem valores sociais, conhecimentos, habilidades, atitudes e competências voltadas para a conservação do meio ambiente, bem de uso comum do povo, essencial à sadia qualidade de vida e sua sustentabilidade (art. $1^{\circ}$ ).

Logo, a EA tem o papel de promover a necessidade de integrar o ser humano com o MA. Cada pessoa precisa aprender a ter atitudes mais responsáveis, menos individualistas, menos consumistas, pois para fazer a EA temos que resgatar os valores que contribuem para uma vida mais saudável, sustentável e em equilíbrio com a natureza e os outros seres.

A lei 9795/99 (BRASIL, 1999) reproduz as concepções básicas da EA, que são debatidas pelos educadores e que constam no Programa Nacional de Educação Ambiental (Pronea), se destacando a interdisciplinaridade, o direito coletivo, a sustentabilidade e a capacitação. É necessário compreender que os 
conceitos de EA e MA, estão profundamente ligados no sentido de conscientizar.

A lei $n^{\circ}$ 6.938/81, conhecida como Política Nacional do Meio Ambiente (BRASIL, 1981) estabelece define o MA como "conjunto de condições, leis, influências e interações de ordem física, química e biológica, que permite abriga e rege a vida em todas as formas". Percebemos que as questões que norteiam o MA são de grande importância para o indivíduo, sendo de interesse comum e coletivo de todos a sua preservação e conservação, pois a nossa qualidade de vida depende das ações que os indivíduos buscam com este.

Para Silva (2010) MA é um lugar determinado onde ocorrem relações dinâmicas e em constante interação com os aspectos naturais e sociais. Estas relações acarretam processos históricos e políticos de transformações da sociedade. É bem verdade que a natureza oferece todos os recursos que são necessários à vida do indivíduo. É importante que cada um perceba a sua ligação com o meio, os outros seres e o universo como um todo para que passe a relacionar-se diretamente os problemas que causa ao MA como algo prejudicial a sua vida.

Moura (2002 apud FREITAS; ARAÚJO; SOUZA, 2008, p.1) afirma que,

Ao longo do tempo o homem sempre utilizou os recursos naturais do planeta. Os recursos eram abundantes e a natureza aceitava os despejos de resíduos realizados. Hoje, a questão ambiental é um dos assuntos que mais tem atraído a atenção das pessoas, pela valorização que se dá à qualidade de vida e pela percepção de que as consequências do descaso com o meio ambiente têm conduzido a situações críticas para a própria sobrevivência da humanidade em longo prazo.

O homem tem transformado o meio onde vive pensando em suas necessidades para a sua comodidade, usando para isso os recursos naturais que a natureza dispõe. Com o passar dos anos esses recursos poderão tornarse escassos se não passarmos a viver de forma consciente e sustentável. Nossas ações levarão consequências ao MA e à vida do planeta. A sociedade é responsável pela transformação que causa ao ambiente. É preciso agir com consciência pensando na sustentabilidade para uma melhor qualidade de vida da atual e futura geração do planeta a fim de atender suas próprias necessidades. (2005)

Nesta perspectiva, a sustentabilidade ambiental para Manzini e Vezzoli

refere-se às condições sistêmicas segundo as quais, em nível regional e planetário, as atividades humanas não devem interferir nos ciclos naturais em que se baseia tudo o que a resiliência do planeta permite e, ao mesmo tempo, não devem empobrecer seu capital natural, que será transmitido às gerações futuras (p.27). 
As atitudes dos indivíduos voltadas à natureza muitas vezes geram impactos negativos. O termo sustentabilidade envolve os indivíduos em ações responsáveis, sustentáveis, contribuindo para o desenvolvimento de uma consciência crítica em relação às questões ambientais e sociais, a fim de garantir uma qualidade de vida favorável às futuras gerações.

A responsabilidade do termo sustentabilidade está presente nas discussões ambientais, em assuntos que envolvem a problemática ambiental, em documentos oficiais das conferências bem como nas legislações de vários países, com destaque para a Agenda 21, elaborada na Conferência das Nações Unidas sobre Meio Ambiente e Desenvolvimento Humano, realizada em junho de 1992 no Rio de Janeiro, a RIO-92.

Então, viver de forma mais sustentável não se limita em cuidar apenas da natureza. Viver de maneira mais sustentável é ter boas ideias e ações comunitárias que irão mudar a nossa vida e dos outros seres vivos. É entender que somos membros de uma comunidade e que fazemos parte de uma sociedade, que somos sujeitos no mundo. Isto é sustentabilidade.

A EA como posição reflexiva contribui para uma prática educativa, cabendo a escola uma parcela de contribuição na busca de um novo pensamento voltado para uma mudança cultural e transformação social, possibilitando a fundamentação de uma consciência ambiental incluindo educadores, alunos e sociedade em prol de uma vida em equilíbrio com o MA. É necessário esclarecer que a EA tem um caráter interdisciplinar que se estabelece a partir de diversos saberes relacionados às necessidades do MA. Não se constrói apenas nas ciências naturais, mas, em todas as disciplinas, pois as questões ambientais estão presentes nos aspectos sociais, culturais, econômicos e políticos com o qual o ambiente interage.

A EA como característica interdisciplinar proporciona uma articulação entre as diferentes disciplinas favorecendo uma compreensão voltada aos assuntos que norteiam esse tema garantindo assim uma interação entre os educadores e alunos e comunidade escolar. Desse modo a EA é um tema transversal presente nas diferentes áreas do conhecimento, de acordo com os PCN (BRASIL, 1997) e envolve questões sociais no contexto escolar, contribuindo para a formação de futuros cidadãos voltados para o exercício a cidadania.

Os PCN (BRASIL, 1997) concebem a educação escolar como:

uma prática que tem a possibilidade de criar condições para que todos os alunos desenvolvam suas capacidades e aprendam os conteúdos necessários para construir instrumentos de compreensão da realidade e de participação em relações sociais, políticas e culturais diversificadas e cada vez mais amplas, condições estas fundamentais para 0 exercício da cidadania na construção de uma sociedade democrática e não excludente (p. 33). 
Dessa forma a escola não é a única que colabora para solucionar os problemas relacionados ao ambiente, porém cabe a escola e aos educadores uma parcela de contribuição no propósito de ajudar a formar cidadãos com um novo pensamento e práticas sociais comprometidas com o futuro do planeta.

\section{A Educação Ambiental no Contexto Escolar}

O homem constitui sua relação com a natureza a partir do desenvolvimento de valores sociais, culturais, políticos e econômicos. Ou seja, a relação homem e natureza se constroem mediante as necessidades básicas do indivíduo. A falta de comprometimento das pessoas em relação aos problemas ambientais provoca uma urgente transformação no comportamento no sentido de defender as questões ambientais para uma melhor qualidade de vida.

Assim, a educação tem importante papel na formação do sujeito visando transformar, motivar e sensibilizar para a construção de futuros cidadãos responsáveis com a preservação e a sustentabilidade do meio buscando como valores: a ética, o respeito e a solidariedade.

A EA promove a construção do conhecimento para superar os problemas direcionados às questões ambientais que a sociedade vem enfrentando e objetiva o desenvolvimento do pensamento crítico voltado à preservação e recuperação para uma conscientização ambiental, na qual o conhecimento é fundamental para uma relação de aprendizagem. A lei 9795/99 (BRASIL, 1999) a respeito do desenvolvimento da EA no ensino formal dispõe em seu art. $10^{\circ}$ que "a educação ambiental será desenvolvida como uma prática educativa integrada, contínua e permanente em todos os níveis e modalidades do ensino formal".

A escola é o local onde acontece o ensino e aprendizagem. A EA dentro do espaço escolar contribui para um comportamento consciente frente às questões ambientais, atribuindo ao indivíduo responsabilidades para uma mudança de comportamento favorável à preservação ambiental. O educador deve ser o mediador no processo de ensino e aprendizagem através da prática educativa estabelecendo uma aprendizagem voltada à cidadania. Neste cenário a escola colabora para o desenvolvimento da EA ensinando para a cidadania, trabalhando os temas transversais a fim de aprimorar as relações do indivíduo com a sociedade e com o MA para a formação de uma consciência ecologicamente correta.

A escola é um espaço social que proporciona ao aluno estabelecer relações sociais de caráter coletivo. Nesse contexto o educador é parte significante na vida dos alunos através de seus ensinamentos, criando habilidades de conhecimento, fornecendo informações que permitem ampliar seus conhecimentos e expor suas ideias.

Queiroz (2011) afirma que o educador ao exercer o seu papel torna-se como um guia que conduz para novos caminhos, sendo, pois, necessária a 
participação deste na qualidade do ensino para formar indivíduos preocupados em construir uma sociedade comprometida com as questões ambientais a fim de preservar e conservar a qualidade de vida do planeta.

É importante que o educador seja participativo na construção da aprendizagem contribuindo para $o$ desenvolvimento e crescimento do conhecimento do aluno. Que lhe proporcione a possibilidade de descobrir novos caminhos e busque soluções de problemas, permitindo a compreensão do ambiente em sua dimensão, comprometendo-se com valores voltados a preservação do mesmo. Com isto, a responsabilidade do educador no processo da formação voltada à cidadania será ampliada.

Os PCN (BRASIL, 1997) afirmam que cabe ao educador

por meio de intervenção pedagógica, promover a realização de aprendizagem com o maior grau de significado possível, uma vez que esta nunca é absoluta. Sempre é possível estabelecer relação entre o que se aprende com a realidade, conhecer possibilidade de observação, reflexão e informação que 0 sujeito já possui. (p. 35).

A escola é o espaço que proporciona ao aluno a oportunidade de aprender a interagir com outros grupos sociais buscando a preparação para o convívio em sociedade. É necessário o convívio com a escola para que o aluno desenvolva um comportamento construtivo visando uma sociedade justa em equilíbrio com o MA e as outras pessoas.

É importante que os indivíduos enquanto sujeitos no mundo façam interações com outras pessoas e outros grupos sociais. A participação da família é importante no processo construtivo para a vida, porém não é suficiente, nesse sentido é indispensável à contribuição da escola bem como do educador para desenvolver atitudes corretas relacionadas às questões ambientais como (o correto manuseio do lixo), para que aprendam na prática educativa durante a permanência na escola, no intuito de formar para a cidadania.

Queiroz (2011) esclarece que:

a escola abarcou a responsabilidade de preparar o educando para a vida, de educar além de informar, de resgatar valores e reconstruir paradigmas, por isso, os temas transversais foram incorporados nos ensinos fundamental e médio, tento por eixo básico a cidadania (p. 14).

A escola que educa para a vida ensina com o propósito de formar sujeitos conscientes de seu papel como parte integrante do MA. Dessa forma, o educador deve criar situações de aprendizagem onde o aluno perceba a 
compreensão da realidade do dia-a-dia possibilitando abertura às discussões em sala de aula. A EA inserida no contexto escolar pode contribuir para a formação do indivíduo como sujeito consciente e comprometido com as mudanças ambientais, através das práticas pedagógicas desenvolvidas, abordando com os educandos os princípios de sustentabilidade e cidadania.

\section{Lixo uma Problemática Ambiental}

Antes de se falar em lixo como um problema de difícil solução é preciso educar e conscientizar o cidadão e sociedade sobre o impacto que este causa ao ambiente. É preciso entender a importância dos conceitos de EA, MA e Sustentabilidade como instrumento educador que envolve os indivíduos em ações ambientais responsáveis em busca de uma construção de vida mais saudável.

Não há apenas um conceito para a palavra lixo, mas vários. De acordo com Ferreira (2001, p. 430) "lixo é tudo o que se varre da casa, da rua, e se joga fora; entulho, coisa imprestável". Lixo pode ser tudo e qualquer coisa velha, um objeto inútil, que perdeu o seu valor ou tudo aquilo que perdeu sua utilidade. Todas estas definições são coerentes, pois o significado desta palavra depende do valor que cada pessoa atribui às coisas.

Para Oliveira (2006, p. 25) lixo é "definido como qualquer objeto sem valor ou utilidade, ou detrito oriundo de trabalhos domésticos, industriais, etc. que se joga fora". Por está definição, lixo está relacionado com tudo o que se joga fora, entendido como algo de rejeição, exclusão. Por este princípio, um determinado objeto passa a ser considerado lixo quando o mesmo é jogado fora, perdendo, portanto sua finalidade.

A maioria das pessoas não sabe qual o destino do lixo após ser colocado na lixeira, quem é responsável pela coleta e pela limpeza das ruas e, principalmente, o que é feito com estes materiais que jogamos fora. Por isto, a questão do lixo é emergente em nossos dias e é uma preocupação de caráter sanitário, ambiental e social.

Antigamente a população era pequena e não havia preocupação com o destino final do lixo sua composição era por compostos orgânicos e dejetos de comida e sua decomposição acontecia pela ação do próprio tempo. Com o passar do tempo a população passou a produzir materiais para o próprio consumo e, com isso a produção de lixo aumentou, porém ainda não havia passado a ser um problema mundial. No século $X X$, com o desenvolvimento industrial, a sociedade sofreu uma mudança no comportamento passando a ficar mais consumista.

Rodrigues e Cavinatto (1997 apud FREITAS; ARAÚJO; SOUZA, 2008, p.10) afirmam que "no decorrer deste século, a população mundial dobrou de tamanho, porém a quantidade de lixo produzido no mesmo período aumentou numa proporção muito maior". Com o aumento da população, existem mais 
produtos sendo fabricados e mais pessoas para os comprar. Com o consumismo em alta o lixo gerado pelas pessoas passou a ser maior.

O consumismo e a carência de encontrar uma forma ecologicamente correta para o tratamento do lixo são uns dos principais problemas causados por este. Com o desenvolvimento das grandes cidades, o avanço tecnológico e a exigência das pessoas em consumirem, fica evidente o descaso com o MA. Jesus (2011) esclarece que na sociedade capitalista onde vivemos o ter acaba tendo mais valor que o ser.

Mas, o que é consumo e o que é consumismo? Jesus (2011, p.10) explica que "o consumo se enquadra na questão do que é necessário à sobrevivência, e consumismo se tornou uma forma de lazer e satisfação das pessoas". O homem sempre consumiu para a sua sobrevivência, para suprir suas necessidades. Com a transformação da sociedade, as pessoas passaram a ter como valor mais importante o consumo de forma exagerada. É necessário que se entenda esta definição para que se possa compreender o efeito causador sobre a sociedade.

Hoje sabemos que fazemos parte de uma sociedade capitalista, onde as pessoas atribuem valores aos objetos, se preocupam em acompanhar a tecnologia descartando de forma incorreta o que consideram lixo. Assim o consumismo é exagerado e quem sofre com esse descaso é o MA, pois a quantidade de produtos fabricados e vendidos diariamente pelo mercado consumidor reflete a quantidade de lixo gerado. Essa cultura capitalista gera desperdício, outro fator que está ligado diretamente com a quantidade de lixo produzido.

Um dos maiores problemas ambientais da sociedade é o destino final do lixo. O lixo sempre esteve presente no convívio social humano, por muito tempo o homem sempre teve que lhe dar com os problemas causados pela consequente produção e a destinação do lixo. Antes a preocupação das pessoas se mantinha em afastar o lixo do seu meio de convívio, levando e descartando em terrenos distantes das cidades, chamados de lixões. Os lixões são terrenos livres, geralmente encontrados nas periferias, nos quais o lixo é depositado a céu aberto e o solo não recebe nenhum cuidado. Não existe tratamento para o líquido que escorre do lixo, chamado "chorume". Este fenômeno causa danos ao MA, mal cheiro às populações próximas, proliferação de insetos e danos à saúde pública.

Outro local para o despejo do lixo são os aterros controlados e aterros sanitários. Aterro controlado está definido como um conceito entre o lixão e o aterro sanitário. Nele, após a deposição no solo, o lixo recebe uma camada de material inerte, minimizando o mau cheiro e a proliferação de insetos. Já no aterro sanitário o solo recebe um tratamento para receber o lixo, minimizando a contaminação do solo e lençóis freáticos. O aterro deve ser previamente impermeabilizado, o que reduzirá o impacto sobre o meio ambiente.

O homem não mediu as consequências em que o aumento exagerado de lixo descartado ao ambiente provoca. Quem sofre com os resultados é o 
próprio homem, pois o consumo só cresce e com isto o descarte impróprio do lixo só aumenta e tem como consequências danos à saúde pública e a possibilidade de ocorrer enchentes em períodos chuvosos, quando se acumula o lixo em locais indevidos, causando o entupimento de bueiros.

Uma das soluções que o homem criou para minimizar o impacto do lixo sobre o ambiente, é reeducar a sociedade, reciclando o lixo através do sistema de coleta seletiva, onde o lixo é separado em lixeiras apropriadas para que posteriormente seja reciclado ou tenha outra finalidade como compostado ou levado para um aterro sanitário.

Uma importante contribuição é oferecida a sociedade pelo princípio dos três R's - Reduzir, Reutilizar e Reciclar. Reduzir diz respeito ao consumo, ou seja, comprar apenas o necessário sem supérfluos. Reutilizar por mais de uma vez o mesmo objeto para o mesmo fim ou criando outra finalidade de uso. E, por último, a reciclagem que consiste em transformar materiais já usados através do processo de industrialização ou artesanal.

A escola contribui para a formação voltada a cidadania. Santos (2008) esclarece que a escola tem um papel fundamental no processo de educação, e ao tratar de EA, pode ser um instrumento de mudança de busca pela qualidade de vida da sociedade". Portanto é necessário o aprendizado sobre a EA no contexto escolar para conscientizar, sensibilizar e ensinar os alunos, contribuindo para um comportamento crítico e responsável diante das questões ambientais. E preciso educar os indivíduos em relação a questão do lixo com o propósito de diminuir a quantidade deste e promovendo um pensamento crítico sobre as consequências em que um mau direcionamento do lixo provoca ao MA, buscando soluções para este problema.

O lixo como problemática ambiental pode ser trabalhado no contexto escolar de forma interdisciplinar, pois envolve questões direcionadas ao MA além do seu aspecto natural envolvendo a sociedade, a saúde, a educação e a cultura. Assim, é possível levar à reflexão os indivíduos para a preservação, conservação e a sustentabilidade do MA.

\section{Metodologia}

Este trabalho tem como proposta investigar o tema transversal EA dentro do convívio de uma escola, trabalhado com educadores nas diversas áreas do conhecimento e teve o intuito de falar sobre o lixo visto como problemática ambiental.

Para a realização desta pesquisa, foi realizado o estudo em uma escola pública municipal, localizada no bairro Vila da Paz, em Teresina - Piauí, o qual apresenta uma grande população em situação de extrema vulnerabilidade social. A escola funciona o ensino infantil e fundamental do $1^{\circ}$ ao $9^{\circ}$ ano e abrange um grande número de alunos da própria comunidade e outras áreas de Teresina; a escola desenvolve e realiza projetos voltados as questões 
ambientais como iniciativa de conscientização dos alunos frente às problemáticas ambientais.

Trata-se de uma pesquisa de campo com utilização de entrevista para a coleta de dados. A entrevista utilizada foi do tipo semiestruturada com seis perguntas, que abordaram a EA nas diversas áreas do conhecimento e a questão do lixo como problemática ambiental, com educadores de diferentes áreas, como: Português, Matemática, Ciências, da Educação Infantil (que trabalha com crianças da creche) e a Pedagoga da escola. Também houve entrevistas semiestruturadas com corpo gestor da escola, zelador, merendeiras e porteiros da escola, porém com apenas duas questões direcionadas ao lixo.

A participação dos educadores das diferentes áreas do conhecimento se deu com o fim de analisar como abordam a EA e a questão do lixo como problemática ambiental em sala de aula. Ressaltamos a importância de dizer que não apenas o educador na área de ciências é o responsável pela transmissão deste conhecimento, pois todas as áreas do conhecimento podem e devem contribuir para que o aluno possa compreendê-la e posicionar diante dela. A participação do corpo gestor, zelador, merendeiras e porteiros contribuiu para a compreensão sobre o comportamento dos alunos fora do âmbito da sala de aula.

Para Marconi e Lakatos (2009)

A entrevista é um encontro entre duas pessoas, a fim de que uma delas obtenha informações a respeito de determinado assunto, mediante uma conversação de natureza profissional. É um procedimento utilizado na investigação social, para a coleta de dados ou para ajudar no diagnóstico ou tratamento de um problema social (p. 80).

A entrevista é uma forma de coletar informações sobre o tema discutido onde se obtêm respostas rápidas às perguntas realizadas sobre o tema em questão. No final da entrevista as respostas foram comparadas a fim de pensar a relação entre as perguntas com o objetivo de buscar o que se foi proposto ao trabalho.

A escolha pela entrevista semiestruturada se deu pelo fato de haver um roteiro preestabelecido no qual as perguntas podem ser modificadas ou acrescentadas novas caso as respostas não tenha sido claras o suficiente e, ainda assim, mantendo um padrão de entrevista entre todos os investigados. A escolha por este instrumento de coleta de dados também se deu pelo fato de que os resultados são rápidos, uma vez que a entrevista é uma troca de informação entre o que se pretende buscar e as respostas para este fim. 


\section{Resultados e discussão}

As entrevistas realizadas com os professores de português, matemática, ciências, professor da educação infantil e a pedagoga da escola, bem como com a contribuição do corpo gestor da escola, zelador, merendeiras e porteiros possibilitaram a obtenção de dados que apontam como ocorre a EA na instituição investigada e, os seus resultados estão elencados abaixo.

\section{Entrevista com a professora de Português}

Durante a entrevista, a participação da professora de português foi bastante positiva para os resultados desta pesquisa. Para esta professora, a EA é abordada em sala de aula, pois a mesma acredita que é uma maneira de conscientizar o homem em relação às suas atitudes com o meio, sendo a escola responsável pela conscientização dos alunos em relação às questões ambientais e o educador o responsável por orientar os alunos a terem boas atitudes. A mesma afirmou que comenta sobre a questão do lixo em suas aulas, e que a abordagem deste assunto poderá ajudar a manter o espaço escolar limpo, uma vez que existe a interdisciplinaridade entre as diferentes áreas do conhecimento.

Quando questionada sobre a contribuição da escola para conscientizar os alunos quanto ao correto manuseio do lixo, a professora afirmou que a escola contribui através do sistema de coleta seletiva, por meio das orientações dos professores em sala de aula e que esta atitude tem o propósito de manter o ambiente escolar limpo, assim como os zeladores e todos os outros funcionários da escola que orientam os alunos a fazerem o uso da lixeira, principalmente durante a recreação, onde o convívio com os alunos é maior.

Sobre a orientação dos alunos acerca do sistema de coleta seletiva e reciclagem, a professora afirmou que comenta sobre o sistema de coleta seletiva procurando chamar a atenção dos alunos para joguem o lixo nas lixeiras corretas. Porém sobre a reciclagem do lixo não aborda este assunto em sala de aula. Ainda sobre o lixo a professora foi questionada sobre as consequências que um mau direcionamento deste pode trazer ao meio ambiente e à saúde e afirmou que o assunto é comentado em sala de aula, que orienta os alunos que um mau direcionamento deste pode provocar doenças à nossa saúde e à saúde de outras pessoas.

\section{Entrevista com professor de Matemática}

O professor de matemática quando questionado sobre a EA afirmou que o tema é abordado em sala de aula, e que ele comenta sobre o assunto. $O$ docente citado explicou que a EA, quando bem exercida, pode contribuir para despertar o interesse dos alunos quanto às questões ambientais. $O$ professor comentou que a questão do lixo é abordada em sala de aula, pois os livros trazem conteúdos interdisciplinares sobre outros assuntos e afirmou que já aconteceu em sala durante uma atividade resolver um problema de matemática 
que envolvia a questão do lixo. O problema pedia para calcular a quantidade de lixo que cada pessoa sozinha produzia diariamente; o professor não recordou sobre o enunciado da pergunta mas afirmou o que mais chamou atenção dos alunos foi a quantidade de lixo que uma pessoa sozinha produz por dia. A partir daí procurou explicar aos seus alunos que economizem suas folhas de papel para não gerar tanto lixo.

Quando questionado sobre a contribuição da escola quanto ao correto manuseio do lixo afirmou que a escola contribui muito pouco e que poderia contribuir mais, realizando mais ações, tais como uma feira de ciência realizada no ano de 2011, pois, para ele, esta feira ajudou a promover a conscientização dos alunos em relação às questões do lixo e resultou na diminuição na quantidade de folhas de papel desperdiçadas diariamente.

Sobre as orientações para os alunos acerca do sistema de coleta seletiva e reciclagem afirmou que muito pouco se comenta sobre o assunto. Em relação ao destino incorreto do lixo e às consequências que este pode causar ao meio ambiente e à saúde das pessoas, o professor de matemática afirmou, de maneira breve, que comenta com os alunos que o destino incorreto do lixo traz consequências à própria saúde.

\section{Entrevista com a professora de Ciências}

A professora de ciências ao ser questionada sobre a EA afirmou que este assunto é abordado em sala de aula em todas as suas turmas. Explicou que em algumas turmas o livro não aborda assuntos relacionados ao MA e que ela contribui para este assunto através de textos complementares sobre reciclagem, lixo, sustentabilidade e outros. A professora explicou que o papel da escola sobre EA direcionada às questões ambientais está presente a partir dos anos iniciais. A mesma acredita que as crianças devem ser ensinadas desde cedo para desenvolverem um comportamento sobre as questões ambientais. Afirmou ainda que a questão do lixo é abordada em sala de aula, buscando sempre falar da importância de se jogar o lixo dentro das lixeiras independente das séries ou do conteúdo que o livro aborda.

Quando questionada sobre a contribuição da escola em relação ao correto manuseio do lixo, afirmou que a escola contribui com a questão do lixo através da direção da escola e de toda a comunidade escolar: professores, orientadores, zeladores e outros funcionários da escola; a mesma comentou que explica aos alunos que um ambiente escolar limpo proporciona bem estar e que o lixo colocado nas lixeiras facilita o seu transporte, além de ajudar as pessoas que trabalham fazendo a limpeza da escola.

Sobre a orientação para os alunos acerca da coleta seletiva e reciclagem afirmou que fala sobre o sistema de coleta seletiva, mas que o assunto reciclagem não é comum em todos os conteúdos. Em relação ao destino incorreto do lixo e às consequências que este pode causar ao meio ambiente e à saúde das pessoas, a professora afirmou que lembra os alunos que o destino incorreto do lixo pode provocar propagação de mosquitos Revbea, São Paulo, V. 9, N²: 344-363, 2014.

revista brasileira educação ambiental 
causando doenças; a questão do saneamento básico, que em muitos bairros a situação ainda é bastante precária; a importância da auto-higienização e que o simples ato de lavar as mãos antes do lanche evita a autocontaminação. Dessa forma falou de muitos assuntos que estão relacionados com o lixo.

\section{Entrevista com a professora da Educação Infantil}

A professora da educação infantil também participou da pesquisa e quando foi questionada sobre a EA afirmou que trabalha o tema em sala de aula. Comentou que, quando trabalha com corte e colagem procura sempre orientar os alunos a manterem a sala de aula limpa e jogar o lixo produzido nas lixeiras. Afirmou que o tema pode contribuir de várias maneiras, percebendo o assunto como uma necessidade de conscientização do homem em lhe dar com o meio para sua sobrevivência e equilíbrio da própria vida.

A professora comentou também que a escola tem a função de mostrar essa visão para os alunos e que o papel do professor é instigar os seus alunos para que estes se conscientizem sobre os assuntos ambientais como o lixo. Quanto à questão do lixo, ela afirmou que esta é trabalhada diariamente nos corredores da escola, pelos professores, zeladores, pedagogas e demais funcionários da escola, que colaboram para que o ambiente escolar permaneça limpo.

Quando questionada sobre a contribuição da escola em relação ao correto manuseio do lixo, afirmou que a escola contribui bastante, através da coleta seletiva, projetos realizados na área de ciências, como o projeto de reciclagem, as visitas à comunidade com 0 intuito de se observar 0 saneamento básico e o acúmulo de lixo nos locais incorretos. Sobre a orientação para os alunos acerca do sistema de coleta seletiva e reciclagem, a mesma afirmou que existe o sistema de coleta seletiva na escola, porém falta influência por parte dos professores. Para ela, precisa-se trabalhar mais sobre a coleta seletiva. Sobre reciclagem, afirmou que não comentou em sala de aula.

Sobre o destino incorreto do lixo e as consequências que este pode causar ao MA e à saúde das pessoas, afirmou que os projetos realizados na escola direcionados à comunidade servem para mostrar aos alunos que o destino incorreto do lixo pode causar doenças e também explicou que comenta sobre a auto-higienização e a importância do ato de se lavar as mãos.

\section{Entrevista com a Pedagoga da escola}

A pedagoga da escola quando questionada sobre a EA comentou que o assunto tem um papel muito importante dentro da escola, porém acredita que seja um assunto novo nesse contexto. Ela afirmou que a EA pode contribuir muito no espaço escolar, fazendo a diferença quando praticada. Quanto à questão do lixo, a mesma explicou que o assunto é abordado em sala de aula através dos professores e fora da sala também, nas reuniões de pais e 
mestres, quando pedem a colaboração dos pais para que, junto com a escola, ensinem os filhos a manter o espaço escolar limpo e a produzirem menos lixo.

Quando questionada sobre a contribuição da escola acerca do correto manuseio do lixo, afirmou que a escola contribui de forma muito significativa sobre essa questão. Segundo ela a escola tem muitas atribuições que não os compete e que o educador tem muita influência na vida dos alunos, entre as quais tem atribuição de: orientar, ensinar e instigá-los. A questão do lixo é uma maneira do educador buscar junto aos alunos uma forma de conscientização, produzindo dessa forma, o ensinamento.

Quando questionada sobre a orientação para os alunos acerca do sistema de coleta seletiva e reciclagem, a mesma explicou que falta influência dos professores quanto ao uso do sistema de coleta seletiva. A respeito da reciclagem na escola comentou que existe uma oficina de reciclagem acompanhada pela professora de artes. Sobre o destino incorreto do lixo e as consequências que este pode causar ao MA e à saúde das pessoas, afirmou que os professores abordam o assunto por meio dos conteúdos que o livro traz e que a escola orienta quanto à conscientização da auto-higienização a fim de promover benefícios à própria saúde.

\section{Entrevista com o corpo gestor, zelador, merendeiras e porteiros da escola}

Durante as visitas à escola para a coleta de dados, a corpo administrativo da escola, o zelador, merendeiras e porteiros também colaboraram para a realização deste estudo, pois forneceram informações sobre o comportamento dos alunos a respeito do correto manuseio do lixo a fim de saber se as orientações dos professores em sala de aula contribuem para um comportamento positivo sobre a questão do lixo escolar. Eles ressaltaram a importância de que a educação não acontece apenas através dos educadores. Todos os outros funcionários da escola podem contribuir para promover o desenvolvimento no processo de ensino e aprendizagem buscando a formação do aluno para a cidadania.

A auxiliar administrativa afirmou que os alunos são pouco atentos para a questão do lixo e que os professores ensinam os alunos em sala de aula sobre a questão do lixo, através dos conteúdos que os livros trazem. Afirmou ainda, em conformidade com o zelador, que os outros funcionários da escola contribuem para a conscientização dos alunos quanto ao correto manuseio do lixo através das orientações para que os alunos joguem o lixo nas lixeiras, principalmente no recreio onde a quantidade de lixo é grande. As merendeiras afirmaram que durante o recreio a quantidade de lixo no pátio é muito grande principalmente porque os alunos espalham restos de comida durante o lanche.

Os porteiros explicaram que os funcionários da escola orientam os alunos a jogarem o lixo nas lixeiras, mas que alguns alunos não são atentos. Explicaram ainda que na entrada da escola existem lixeiras e que eles mesmos orientam os alunos a jogarem o lixo nelas, dessa maneira mantendo o espaço externo limpo. 
As entrevistas mostraram que os professores das diferentes áreas do conhecimento abordam o tema EA em seus conteúdos habitualmente trabalhados em sala de aula, entendendo que o tema é necessário para uma mudança no comportamento do indivíduo sobre as questões ambientais. Quanto à questão do lixo os resultados obtidos na entrevista mostraram que todos os professores abordam o assunto em sala de aula, de maneira interdisciplinar. Através do conteúdo que os livros trazem, das orientações quanto ao uso da lixeira, por meio dos projetos realizados na comunidade e na própria escola, dessa forma contribuindo para a conscientização dos alunos frente às questões ambientais.

Sobre as orientações da reciclagem do lixo e acerca do sistema de coleta seletiva apenas as professores de português e ciências comentam sobre o sistema de coleta seletiva com os alunos. Já os professores de matemática e da educação infantil, não orientam os alunos quanto ao sistema de coleta seletiva afirmando existir uma falha nesse sistema. Apenas a professora de Ciências aborda o assunto de reciclagem em sala de aula.

A partir dos dados coletados para a realização deste trabalho pode-se concluir que a escola investigada contribui para a promoção da EA nas diferentes disciplinas, os professores de português, matemática e da educação infantil abordam o tema transversal EA em seus conteúdos tradicionais de sala de aula. O resultado do estudo mostrou que os educadores em suas diferentes áreas do conhecimento, pedagoga, zelador, merendeiras, porteiros e todos outros funcionários da escola são responsáveis por contribuir e promover o conhecimento frente às questões ambientais.

A entrevista também mostrou como ponto negativo o sistema de coleta seletiva. O sistema é recente e pouco desenvolvido por parte dos professores e de toda a escola. Não existem orientações quanto ao uso das lixeiras o que, segundo a pedagoga da escola, ocorre por falta de influência da escola para 0 correto uso desse sistema no ambiente escola.

Para Monteiro (2010, p.14) a EA tem o papel de fomentar a percepção da necessária integração do ser humano com o MA. Para a autora (idem) este equilíbrio dinâmico natural, possibilita, por meio de novos conhecimentos, valores e atitudes, a inserção do educando e do educador como cidadãos no processo de transformação do atual quadro ambiental do planeta.

A participação da escola neste trabalho foi importante no sentido de contribuir para o desenvolvimento de um conhecimento crítico voltado à preservação, a sustentabilidade e à conservação ambiental. Monteiro (2010, p. 16) afirma que a escola

é o espaço social e o lugar onde o aluno dará sequência ao seu processo de socialização. É de extrema importância que cada aluno desenvolva as suas potencialidades e adote posturas pessoais e comportamentos sociais construtivos, colaborando para a contemplação de uma sociedade socialmente justa, em um ambiente saudável.

Revbea, São Paulo, V. 9, № 2: 344-363, 2014. 
Os educadores nas diferentes áreas do conhecimento foram chamados a participar, visando analisar se estes abordam a EA de maneira interdisciplinar em seus conteúdos habitualmente trabalhados em sala de aula. Silva (2010, p.23) esclarece que a característica interdisciplinar da EA proporciona uma abordagem ampla dos olhares em direção ao MA, pois considera as colaborações das diferentes esferas de conhecimento, garantindo uma compreensão favorável e maior integração entre alunos, professores e comunidade escolar.

Portanto é importante se trabalhar o tema com crianças, pois é a partir da reflexão destes sobre a vida, sobre o mundo e sobre si mesmas que poderemos garantir uma vida mais sustentável e equilibrada para todos no futuro. Queiroz (2011) acredita que atualmente

educação exige que não apenas os educadores, alfabetizadores, orientadores sejam multifuncionais, mas também os psicólogos, pedagogos, filósofos, sociólogos, psicopedagogos, entre outros, para que possam desenvolver as habilidades e a confiança necessária em seus educandos e em sua comunidade escolar, objetivando sucesso no processo de ensino (p. 12).

Assim o educador tem um papel decisivo sobre a inserção da EA no intuito de qualificar o aluno para que este desenvolva um pensamento crítico voltado às questões ambientais. A escola contribui para um desenvolvimento de um pensamento sustentável como meio de conscientização ambiental buscando construir um conhecimento participativo através da prática pedagógica.

\section{Conclusões}

A discussão sobre Educação Ambiental e o lixo se apresenta como uma necessidade, pois a sociedade está vivendo um momento de carência de um conhecimento crítico voltado às questões de preservação, conservação e sustentabilidade ambiental. Faz-se necessário uma compreensão do conceito de meio ambiente que não se traduz apenas em seu meio natural, contemplando também a sociedade, a educação, a cultura e a saúde e considera importante a ideia do termo sustentabilidade como prática coletiva voltada a conscientização ambiental.

Nesse entendimento a EA no contexto escolar contribui para o desenvolvimento de um comportamento construtivo dos alunos como favorecimento de um pensar crítico voltado à responsabilidade ambiental, social e cultural. Dessa forma a escola tem um papel importante à medida que se responsabiliza pela formação do indivíduo como cidadão no mundo. Neste contexto, o educador exerce um papel importante no processo de construção 
do conhecimento do aluno, por meio do ensinamento que promove 0 desenvolvimento intelectual contribuindo para a construção da vida social.

A EA como tema transversal deve ser inserida no contexto escolar por todos os educadores nas diferentes áreas do conhecimento com o propósito de instruir os alunos frente às questões ambientais, para que estes façam questionamentos, busquem soluções sobre a realidade em favor de um meio ambiente e um pensamento sustentável.

A pesquisa abordou a questão do lixo como problemática ambiental ressaltando que um mau direcionamento deste gera impacto negativo ao MA, cabendo ao homem buscar alternativas para a sua destinação final como os lixões, aterros sanitários e aterros controlados, ou encontrar possíveis soluções como o sistema de coleta seletiva e a reciclagem.

É importante inserir a questão do lixo como problemática ambiental ao tema EA no contexto escolar de modo que se compreenda a importância do assunto, fazendo com que os alunos reflitam sobre essa realidade com 0 propósito de educar e conscientizar as crianças contribuindo para uma vida mais sustentável haja vista, as consequências em que o lixo causa ao MA no nosso dia-a-dia. Enfatizamos que a pesquisa ocorreu em uma escola que já realiza trabalhos com a temática ambiental e que os resultados desta pesquisa indicam que, para se ter bons resultados, todos da comunidade escolar têm que estar trabalhando juntos. Acreditamos que a realidade encontrada na escola investigada encontra-se bem diferente da maioria das demais e que pode nos apontar um bom caminho a ser seguido.

Para tanto a EA no contexto escolar como instrumento de ensino contribui no sentido de forma o aluno para a cidadania. Na escola, a partir do momento em que se responsabiliza pela formação dos alunos enquanto cidadãos, a aprendizagem será mais efetiva a partir do desenvolvimento de um conhecimento crítico sobre as questões ambientais, atitudes e habilidades necessárias a melhoria da qualidade de vida do planeta.

\section{Referências}

BRASIL. Constituição - República Federativa do Brasil de 1988. Brasília: 1988. BRASIL. Lei no 6.938, de 31 de agosto de 1981. Dispõe sobre a Política Nacional do Meio Ambiente, seus fins e mecanismos de formulação e aplicação, e dá outras providências. Disponível em http://www.planalto.gov.br/ccivil 03/leis/l6938.htm. Acesso em 08 fev. 2013.

BRASIL. Lei $n^{\circ}$ 9.795, de 27 de abril de 1999. Dispõe sobre a educação ambiental, institui a Política Nacional de Educação Ambiental e dá outras providências. Brasília: 1999. Disponível em http://www.planalto.gov.br/ccivil 03/leis/l9795.htm. Acesso em 08 fev. 2013.

BRASIL. Parâmetros Curriculares Nacionais. Brasília: MEC/SEF, 1997.

FERREIRA, A.B.H. Miniaurélio Século XXI Escolar: O minidicionário da língua portuguesa. 4. ed. Rio de Janeiro: Nova Fronteira, 2001.

Revbea, São Paulo, V. 9, № 2: 344-363, 2014. 
FREITAS, J.S; ARAÚJO, J.J.C.N.; SOUZA, J.V.F. Questões ambientais da atualidade: a problemática do lixo em Cruzeiro do Sul (AC). 2008. Disponível em http://artigos. netsaber.com.br/resumo artigo 8301/artigo sobre questoes ambien tais da atualidade. Acesso em 21 jan. 2013.

JESUS, V.L.A.C. O consumismo infantil e a degradação ambiental: uma análise sobre hábitos e atitudes de alunos do $2^{\circ}$ segmento do ensino fundamental/município do RJ. 44f. 2011. Monografia (Especialização em Docência do Ensino Superior) - AVM Faculdade Integrada, Rio de Janeiro, 2011. Disponível em www.avm.edu.br/docpdf/monografias publicadas/t206686.pdf. Acesso em 21 jan. 2013.

MANZINI, E.; VEZZOLI, C. O desenvolvimento de produtos sustentáveis: os requisitos ambientais dos produtos industriais. São Paulo: Editora da Universidade de São Paulo, 2005.

MARCONI, M.A.; LAKATOS, E.M. Técnicas de pesquisa. 7. ed. São Paulo: Atlas, 2009.

MONTEIRO, F.C. A Educação Ambiental em Ciências do Ensino Fundamental Brasileiro. 46f. 2010. Monografia (Especialização em Educação Ambiental) Instituto a Vez do Mestre, Universidade Cândido Mendes, Rio de Janeiro, 2010. Disponível em www.avm.edu.br/docpdf/monografias publicadas/t205824.pdf. Acesso em 20 fev. 2013.

OLIVEIRA, I.C.P. Lixo na "escada": Um estudo sobre a gestão municipal de resíduos sólidos. 125f. 2006. Dissertação (Mestrado em Gestão Ambiental) Programa de Pós-Graduação em Ciência Ambiental, Departamento de Análise Geoambiental, Instituto de Geociências, Universidade Federal Fluminense, Niterói, 2006. Disponível em www.uff.br/cienciaambiental/dissertacoes/lCPOliveira.pdf. Acesso em 23 fev. 2013.

QUEIROZ, T.D. Manual pedagógico: do educador da educação e dos anos iniciais do ensino fundamental. São Paulo: Rideel, 2011.

RODRIGUES, V.L. Educação Ambiental: Ferramenta para a Construção da Cidadania. 62f. 2010. Monografia (Especialização em Educação Ambiental) Instituto a Vez do Mestre, Universidade Cândido Mendes, Rio de Janeiro, 2010. Disponível em www.avm.edu.br/docpdf/monografias publicadas/t206328.pdf. Acesso em 20 fev. 2013.

SANTOS, R.G. Aprendendo sobre o lixo urbano: um olhar da ecologia integral. $50 f$. 2008. Monografia (Graduação em Licenciatura em Química) - Faculdade de Educação, Universidade Federal de Minas Gerais, Belo Horizonte, 2008. Disponível em http://www.cecimig.fae.ufmg.br/wpcontent/uploads/2008/12/aprendendo-sobre-o-lixo-urbano.pdf. Acesso em 10 mar. 2013.

SILVA, D.C. A Educação ambiental no contexto escolar... como prática participativa. 44f. 2010. Monografia (Especialização) - Instituto a Vez do Mestre, Universidade Cândido Mendes, Rio de Janeiro, 2010. Disponível em www.avm.edu.br/docpdf/monografias publicadas/t205898.pdf. Acesso em $14 \mathrm{fev}$. 2013. 